УДК 674.032.475.3:547.458.7:547.917

\title{
ИССЛЕДОВАНИЕ КАМЕДИ ЛИСТВЕННИЦЫ ГМЕЛИНА (LARIX GMELINII (RUPR.) RUPR.)
}

\author{
() Н.А. Неверова ${ }^{*}$ Е.Н. Медведева, А.А. Левчук, В.А. Бабкин
}

\author{
Иркутский институт химии им. А.Е. Фаворского СО РАН, ул. Фаворского, 1, \\ Иркутск, 664033 (Россия), e-mail: nadya_neverova@irioch.irk.ru
}

Методами гельпроникающей хроматографии, ИК, количественной спектроскопии ЯМР ${ }^{13} \mathrm{C}$ и спектрофотометрии исследованы образцы камеди лиственницы Гмелина (Larix gmelinii (Rupr.) Rupr.), отобранные с различных деревьев и с разных частей дерева в окрестностях г. Улан-Удэ (Республика Бурятия). Образцы растворяли в дистиллированной воде при комнатной температуре. Механические примеси отделяли фильтрованием, прозрачные растворы упаривали досуха, сухие остатки очищали переосаждением из воды в этанол. Содержание механических примесей составило 0,1-4,8\% от массы а. с. камеди. Водные растворы камеди имеют слабокислую реакцию, как и АГ, выделенный из древесины лиственниц сибирской и Гмелина. Установлено, что камедь лиственницы Гмелина представляет собой арабиногалактан высокой степени чистоты ( $99 \%)$ с незначительными примесями флавоноидов, таннинов, минеральных веществ. По молекулярно-массовым характеристикам и моносахаридному составу он аналогичен арабиногалактану, выделенному из древесины всех ранее исследованных видов лиственницы, произрастающих в Сибири и на Дальнем Востоке. Полученные данные позволяют рекомендовать камедь лиственницы Гмелина для применения в медицине, ветеринарии, пищевой и косметической промышленности.

Ключевые слова: камедь лиственницы, арабиногалактан, физико-химические свойства, моносахаридный состав, молекулярно-массовое распределение.

Работа выполнена при финансовой поддержке Программы Президиума РАН № 8 «Химический анализ и исследование структуры веществ: фундаментальные основы и новые методы. Разработка методов получения химических веществ и создание новых материалов. Физико-химические проблемы поверхностных явлений»

\section{Введение}

Камеди, или гумми, представляют собой густую массу, появляющуюся при механических повреждениях или болезнях на коре дерева, быстро застывающую и твердеющую на воздухе. Камедь лиственницы выделяется в большом количестве на обгорелых стволах и пнях при лесных пожарах [1]. В литературе сведения о точном химическом составе и физико-химических свойствах лиственничной камеди практически отсутствуют. Согласно [2], камедь - это комбинации углеводов (пентозаны и гексозаны) с калиевыми, магниевыми и кальциевыми солями органических кислот. В работе [3], посвященной исследованию термических свойств натечной камеди лиственницы, установлено, что она на 96,8\% состоит из арабиногалактана (АГ), однако вид лиственницы не указан и физико-химические свойства АГ не исследованы.

Камеди нерастворимы в спирте, эфире, ацетоне, хлороформе, но в воде они полностью или частично рас-

Неверова Надежда Анатольевна - кандидат химических наук, научный сотрудник, e-mail: nadya_neverova@irioch.irk.ru

Медведева Елена Николаевна - кандидат химических наук, старший научный сотрудник,

e-mail: woodemed@irioch.irk.ru

Левчук Алексей Александрович - кандидат технических наук, научный сотрудник, e-mail: levchuk@irioch.irk.ru Бабкин Василий Анатольевич - доктор химических наук, профессор, заведующий лабораторией химии древесины, e-mail: babkin@irioch.irk.ru творяются, образуя обладающие клеящими свойствами коллоидные растворы, которые могут применяться для склеивания древесных частиц без добавления к ним связующих $[1,2]$. Камедь применяется в текстильной промышленности, в спичечном и кондитерском производстве, а также в медицине [2]. Камедь сибирской лиственницы может вполне заменить гуммиарабик при изготовлении офсетных печатных форм [1].

\footnotetext{
* Автор, с которым следует вести переписку.
} 
Лиственничная камедь обладает противовоспалительными, противомикробными, вяжущими, ранозаживляющими, противоцинготными, обезболивающими и общеукрепляющими свойствами. Она активизирует пищеварительные рефлексы, оказывает благоприятное воздействие на слизистую желудка, пищевода, верхних дыхательных путей, полости рта, действует как антисептик против золотистого стафилококка. В народной медицине Прибайкалья камедь является универсальным средством против изжоги и заболеваний желудка (гастрит, язва). В тибетской медицине ее применяют для профилактики рака, как адаптогенное, иммуностимулирующее, обволакивающее средство [4]. Камедь лиственницы входит в состав известного гигиенического средства «Малавит» [5].

Цель данного исследования - изучение физико-химических свойств натечной камеди лиственницы Гмелина с перспективой ее практического применения.

\section{Экспериментальная часть}

Исследовались образцы камеди лиственницы Гмелина (Larix gmelinii (Rupr.) Rupr.), отобранные с различных деревьев и с разных частей дерева в окрестностях Улан-Удэ (Республика Бурятия), представляющие собой полупрозрачную стекловидную массу от янтарного до темно-коричневого цвета со смолистым запахом. Образцы растворяли в дистиллированной воде при комнатной температуре. Нерастворившиеся механические примеси отделяли фильтрованием, прозрачные растворы выпаривали досуха. Продукт очищали переосаждением из водного раствора в пятикратный избыток этанола. Осадок на фильтре промывали небольшим количеством этанола, затем ацетоном и высушивали до постоянной массы. Содержание флавоноидов в неочищенных сухих остатках и в очищенных переосаждением образцах определяли на спектрофотометре Unico S2100 по интенсивности поглощения их комплексов с хлоридом алюминия при 400 нм, содержание таннинов - по интенсивности поглощения водных растворов образцов при 440 нм [6].

Молекулярно-массовые характеристики образцов определяли методом гельпроникающей хроматографии с помощью хроматографической системы Agilent 1260 на колонке PL aquagel-OH-40 8 мкм, $300 \times 7,5$ мм, с предколонкой PL aquagel-OH Guard 8 мкм, $50 \times 7,5$ мм, откалиброванной по растворам стандартов - декстранов с молекулярной массой 25, 12 и 5 кDa и D-галактозы. Термостатирование колонки при $25^{\circ} \mathrm{C}$. Спектры регистрировали на рефрактометрическом детекторе, термостатирование ячейки при $30{ }^{\circ} \mathrm{C}$. Элюент - 0,1M раствор $\mathrm{LiNO}_{3}$, скорость подачи 1,0 мл/мин, объем петли дозатора 20 мкл [7]. Степень полидисперсности макромолекул полисахарида определяли как соотношение среднемассовой и среднечисловой молекулярной массы $\left(\mathrm{M}_{\mathrm{w}} / \mathrm{M}_{\mathrm{n}}\right)$.

Спектры ЯMP ${ }^{13} \mathrm{C}$ регистрировали на спектрометре Bruker DPX 400 с рабочей частотой 100 МГц, растворитель - $\mathrm{D}_{2} \mathrm{O}$. Соотношение звеньев галактозы и арабинозы в составе макромолекул $\mathrm{A \Gamma}$ (Gal/Ara) рассчитывали по соотношению интегральных интенсивностей сигналов аномерных атомов углерода галактозы и арабинозы [8]. ИК спектры регистрировали в таблетках с KBr на спектрофотометре Specord 75 IR в интервале $500-4000 \mathrm{~cm}^{-1}$.

\section{Обсуждение результатов}

Механические примеси составляют 0,1-4,8\% от массы а. с. камеди. Водные растворы камеди имеют слабокислую реакцию, как и АГ, выделенный из древесины лиственницы сибирской и Гмелина. В ИК спектрах как неочищенных, так и очищенных образцов (рис. 1) наблюдается интенсивная широкая полоса поглощения в области 3600-3200 см-1, соответствующая валентным колебаниям гидроксильных групп, связанных водородными связями. Деформационным колебаниям гидроксильных групп соответствует полоса в области 1636-1641 $\mathrm{cm}^{-1}$.

Валентные колебания $\mathrm{CH}_{2}-$ и $\mathrm{CH}-$ групп углеводных звеньев проявляются полосой поглощения в области 2922-2924 см-1, а деформационные - полосой поглощения в области 1377-1378 $\mathrm{cm}^{-1}$. Валентным колебаниям эфирной С-О-С связи соответствует полоса поглощения при $1150 \mathrm{~cm}^{-1}$, валентные колебания С-ОН связи проявляются интенсивной полосой в области 1076-1077 см-1. Полосы 775 и $879-884$ см$^{-1}$ подтверждают присутствие в структуре арабиногалактана из камеди лиственницы $\beta$-гликозидной связи пиранозного кольца. ИК спектры всех образцов камеди идентичны и соответствуют спектру высокочистого АГ, приведенному в работе [9].

Спектры ЯМР ${ }^{13} \mathrm{C}$ очищенных и неочищенных образцов идентичны и соответствуют спектрам АГ из древесины лиственницы сибирской $[10,11]$. 


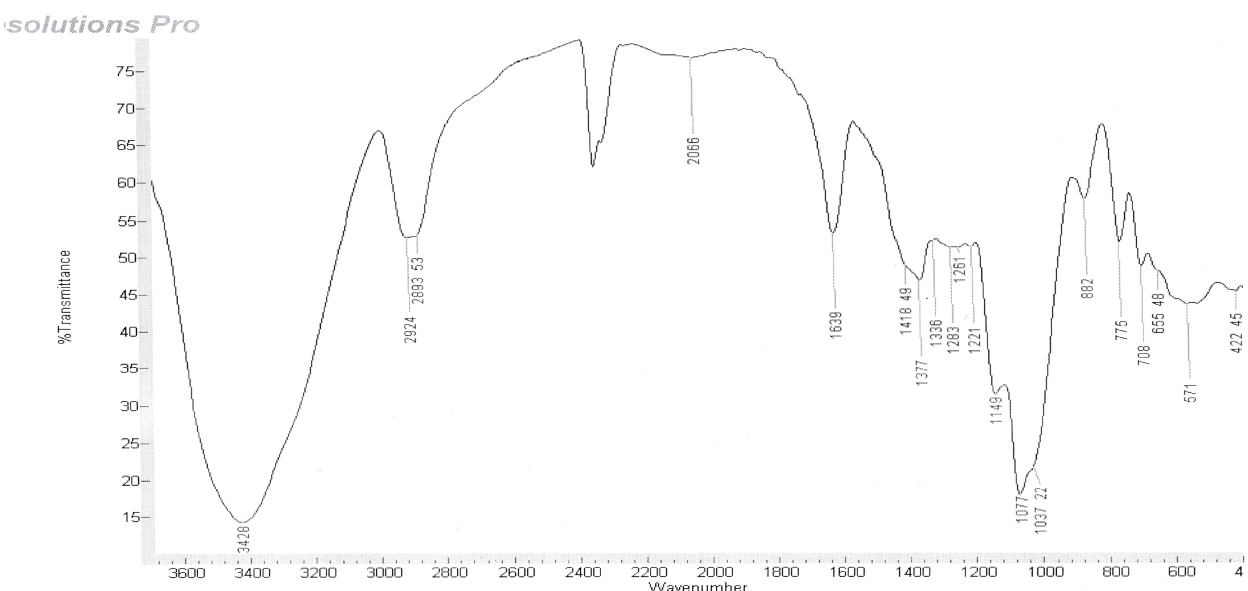

Рис. 1. ИК спектр лиственничной камеди

Отсутствие в ИК спектрах поглощения в области $\sim 1700 \mathrm{~cm}^{-1}$, а также сигналов в области 200-220 м.д. в спектрах ЯМР ${ }^{13}$ С свидетельствует об отсутствии кислотных карбонильных групп в макромолекулах АГ лиственничной камеди. Этим он отличается от АГ, выделенного авторами [3], в котором обнаружено 6,5\% карбоксильных групп.

Представленные в таблице 1 данные свидетельствуют о том, что неочищенные продукты (сухие остатки растворов) содержат незначительные количества фенольных и неорганических примесей.

Полученные результаты позволяют сделать вывод о том, что исследованные образцы лиственничной камеди представляют собой арабиногалактан высокой степени чистоты. Очистка переосаждением позволяет полностью удалить неорганические примеси и значительно снизить содержание флавоноидов и таннинов. В работе [3] АГ из натечной камеди лиственницы, очищенный с использованием полиамидного сорбента, имел практически такую же степень чистоты (зола - 0,3\%, фенольные вещества - следы).

По данным ВЭЖХ очищенные образцы АГ имеют довольно близкие значения средней молекулярной массы и степени полидисперсности (рис. 2, табл. 2). Образцы 1 и 2 содержат небольшое количество олигомерных продуктов $(\sim 1,5-3,0 \%)$.

Таблица 1. Свойства лиственничной камеди лиственницы Гмелина

\begin{tabular}{|c|c|c|c|c|c|c|c|c|}
\hline \multirow{3}{*}{ 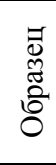 } & \multirow{3}{*}{ Место отбора пробы } & \multirow{3}{*}{$\begin{array}{c}\mathrm{pH} \\
\text { раствора }\end{array}$} & \multicolumn{6}{|c|}{ Содержание, \% } \\
\hline & & & \multicolumn{2}{|c|}{ Флавоноиды } & \multicolumn{2}{|c|}{ Таннины } & \multicolumn{2}{|c|}{ Зола } \\
\hline & & & $\begin{array}{l}\text { в сухом } \\
\text { остатке }\end{array}$ & $\begin{array}{c}\text { в очищ. } \\
\text { АГ }\end{array}$ & $\begin{array}{l}\text { в сухом } \\
\text { остатке }\end{array}$ & $\begin{array}{c}\text { в очищ. } \\
\text { АГ }\end{array}$ & $\begin{array}{l}\text { в сухом } \\
\text { остатке }\end{array}$ & $\begin{array}{c}\text { в очищ. } \\
\text { АГ }\end{array}$ \\
\hline 1 & $\begin{array}{l}\text { Нижнее дупло, 0,1-0,2 м } \\
\text { от земли }\end{array}$ & 3,9 & 0,17 & 0,02 & 0,20 & 0,16 & - & - \\
\hline 2 & Комель, 2 м от земли & 3,2 & 0,32 & 0,03 & 0,42 & 0,20 & 0,23 & - \\
\hline 3 & Ствол, 3-4 м от земли & 4,9 & 0,17 & 0,01 & 0,51 & 0,33 & 0,55 & - \\
\hline
\end{tabular}

Рис. 2. ВЭЖ-хроматограммы образцов 2 и 3 АГ лиственничной камеди

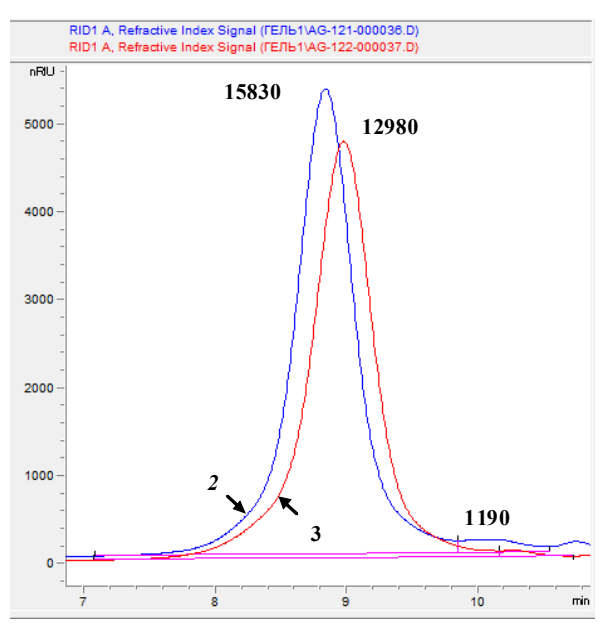


Моносахаридный состав (соотношение Gal/Ara) макромолекул исследованных образцов АГ зависит от места отбора пробы камеди (табл. 2). Такой разброс значений Gal/Ara в зависимости от различных факторов отмечался ранее [12].

В целом по молекулярно-массовым характеристикам и моносахаридному составу арабиногалактан камеди лиственницы Гмелина (табл. 2) практически не отличается от АГ, выделенного из древесины всех исследованных нами ранее видов лиственницы [10].

Таблица 2. Молекулярно-массовые характеристики АГ из камеди

\begin{tabular}{c|c|c|c|c}
\hline Образец* & $\mathrm{MM}$ & Площадь пиков с различной $\mathrm{MM}, \%$ & $\mathrm{M}_{\mathrm{w}} / \mathrm{M}_{\mathrm{n}}$ & Gal/Ara \\
\hline \multirow{2}{*}{2} & 14710 & 98,36 & 1,26 & 15,2 \\
& 1020 & 1,64 & 1,24 & 8,5 \\
& 15830 & 97,17 & & 8,7 \\
\hline
\end{tabular}

* Номера образцов соответствуют приведенным в таблице 1.

\section{Выводы}

Установлено, что камедь лиственницы Гмелина представляет собой арабиногалактан высокой степени чистоты ( $99 \%)$ с незначительными примесями флавоноидов, таннинов и минеральных веществ. По молекулярно-массовым характеристикам и моносахаридному составу он практически не отличается от арабиногалактана, выделенного из древесины всех исследованных нами ранее видов лиственницы, произрастающих в Сибири и на Дальнем Востоке.

Основные результаты исследования получены с использованием материально-технической базы

Байкальского аналитического центра коллективного пользования СО РАН.

\section{Сиисок литературь}

1. Спасский Н.А. Клей для переплетных работ. М., 1953. 264 с.

2. Чудинов Б.С., Тюриков Ф.Т., Зубань П.Е. Древесина лиственницы и ее обработка. М, 1965. 143 с.

3. Терпукова А.Ф., Чочиева М.М., Антоновский С.Д. О термических свойствах арабиногалактана // Химия древесины. 1978. № 2. С. 101-106.

4. Травы Алтая [Электронный ресурс]. URL: http://travialtaya.ru.

5. Малавит [Электронный ресурc]. URL:https://www.malavit.ru.

6. Медведева Е.Н., Остроухова Л.А., Неверова Н.А., Онучина Н.А., Бабкин В.А. Фенольные примеси в арабиногалактане из древесины лиственницы // Химия растительного сырья. 2011. № 1. С. 45-48.

7. Neverova N.A., Levchuk A.A, Ostroukhova L.A., Medvedeva E.N., Onuchina N.A., Babkin V.A. Distribution of Extractive Substances in Wood of the Siberian Larch (Larix sibirica Ledeb.) // Russian Journal of Bioorganic Chemistry. 2013. Vol. 39. N 7. Pp. 712-719.

8. Медведева Е.Н., Федорова Т.Е., Ванина А.С., Рохин А.В., Еськова Л.А., Бабкин В.А. Влияние способа выделения и очистки арабиногалактана из древесины лиственницы сибирской на его строение и свойства // Химия растительного сырья. 2006. № 1. С. 25-32.

9. Антонова Г.Ф., Тюкавкина Н.А. Получение высокочистого арабиногалактана из древесины лиственницы // Химия древесины. 1976. № 4. С. 60-62.

10. Babkin V.A., Neverova N.A., Medvedeva E.N., Fedorova T.E., Levchuk A.A. Investigation of Physicochemical Properties of Arabinogalactan of Different Larch Species // Russian Journal of Bioorganic Chemistry. 2016. Vol. 42. N 7. Pp. 23-27.

11. Karacsonyi S., Kovacik V., Alfoldi J., Kubackova M. Chemical and 13C studies of arabinogalactan from Larix sibirica L. // Carbohydrate Research. 1984. Vol. 134. Pp. 265-274.

12. Медведева Е.Н., Федорова Т.Е., Ванина А.С., Рохин А.В., Еськова Л.А., Бабкин В.А. Влияние способа выделения и очистки арабиногалактана из древесины лиственницы сибирской на его строение и свойства // Химия растительного сырья. 2006. № 1. С. 25-32.

Поступило в редакичию 28 декабря 2016 г. 
Neverova N.A.*, Medvedeva E.N., Levchuk A.A., Babkin V.A. THE RESEARCH OF GMELIN LARCH (LARIX GMELINII (RUPR.) RUPR.) GUM

Irkutsk Institute of Chemistry. A.E. Favorsky, Siberian Branch of the Russian Academy of Sciences, ul. Favorskogo, 1, Irkutsk, 664033 (Russia), e-mail: nadya_neverova@irioch.irk.ru

The samples of Gmelin larch (Larix gmelinii (Rupr.) Rupr.) gum, selected from a variety of trees and from different parts of the tree in vicinities of Ulan-Ude city (Buryatia), were investigated with GPC, IR, quantitative NMR 13C spectroscopy and spectrophotometry methods. The samples were dissolved in distilled water at a room temperature. The mechanical impurities were filtered, the transparent solutions were evaporated to dryness, and the dry residues were purified by reprecipitation from water to ethanol. The content of mechanical impurities was $0,1-4,8 \%$ by the mass of absolutely dry gum. Aqueous solutions of gum are subacidic, as well as AG isolated from wood of Siberian and Gmelin larches. It is established, that Gmelin larch gum is a high purity arabinogalactan $(\sim 99 \%)$ with minor impurities of flavonoids, tannins and mineral substances. Molecular-mass characteristics and monosaccharide composition of Gmelin larch gum arabinogalactan is similar to arabinogalactan recovered from wood of all previously studied species of larch growing in Siberia and the Far East. The data obtained allow recommending Gmelin larch gum for application in medicine, veterinary, the food and cosmetic industry.

Keywords: gum, arabinogalactan, physico-chemical properties, monosaccharide composition, molecular-mass distribution.

\section{References}

1. Spasskii N.A. Klei dlia perepletnykh rabot. [Glue for binding works]. Moscow, 1953, 264 p. (in Russ.).

2. Chudinov B.S., Tiurikov F.T., Zuban' P.E. Drevesina listvennitsy i ee obrabotka. [Larch wood and its processing]. Moscow, 1965, 143 p. (in Russ.).

3. Terpukova A.F., Chochieva M.M., Antonovskii S.D. Khimiia drevesiny, 1978, no. 2, pp. 101-106. (in Russ.).

4. Travy Altaia [Herbs of Altai]. [Elektronnyi resurs]. URL: http://travialtaya.ru (in Russ.).

5. Malavit [Elektronnyi resurs]. URL: https://www.malavit.ru (in Russ.).

6. Medvedeva E.N., Ostroukhova L.A., Neverova N.A., Onuchina N.A., Babkin V.A. Khimiia rastitel'nogo syr'ia, 2011, no. 1, pp. 45-48. (in Russ.).

7. Neverova N.A., Levchuk A.A, Ostroukhova L.A., Medvedeva E.N., Onuchina N.A., Babkin V.A. Russian Journal of Bioorganic Chemistry, 2013, vol. 39, no. 7, pp. 712-719.

8. Medvedeva E.N., Fedorova T.E., Vanina A.S., Rokhin A.V., Es'kova L.A., Babkin V.A. Khimiia rastitel'nogo syr'ia, 2006, no. 1, pp. 25-32. (in Russ.).

9. Antonova G.F., Tiukavkina N.A. Khimiia drevesiny, 1976, no. 4, pp. 60-62. (in Russ.).

10. Babkin V.A., Neverova N.A., Medvedeva E.N., Fedorova T.E., Levchuk A.A. Russian Journal of Bioorganic Chemistry, 2016, vol. 42, no. 7, pp. 23-27.

11. Karacsonyi S., Kovacik V., Alfoldi J., Kubackova M. Carbohydrate Research, 1984, vol. 134, pp. 265-274.

12. Medvedeva E.N., Fedorova T.E., Vanina A.S., Rokhin A.V., Es'kova L.A., Babkin V.A. Khimiia rastitel'nogo syr'ia, 2006, no. 1, pp. 25-32. (in Russ.).

Received December 28, 2016

Revised January 18, 2017

\footnotetext{
* Corresponding author.
} 
